Article

\title{
Experimental Assessment of the Sealing Potential of Hydrated Solgel for the Remediation of Leaky Reservoirs
}

\author{
Maria Garcia-Rios * and Philippe Gouze \\ Géosciences Montpellier, CNRS-Université de Montpellier, Place Eugène Bataillon, 34095 Montpellier, France; \\ philippe.gouze@umontpellier.fr \\ * Correspondence: maria.garcia-rios@umontpellier.fr; Tel.: +33-467-144-258
}

Received: 3 July 2018; Accepted: 30 July 2018; Published: 4 August 2018

\begin{abstract}
The full-scale deployment of underground storage of $\mathrm{CO}_{2}$ in permeable sedimentary reservoirs depends strongly on the sealing capacity of the caprocks and wellbore cement that may be degraded leading to hydraulic discontinuities. Remediation technologies consisting in rebuilding the sealing capacity of the degraded material, or adding a new sealing layer, is a critical issue as part of the risk mitigation procedure required for underground $\mathrm{CO}_{2}$ storage. Actually, engineered Portland cement injection is the foremost available industrial technique; however, alternative products offering, for instance, better injection properties, are currently investigated with variable success so far. In this study, a new technique aimed at using a low viscosity hydrated solgel as sealant product in case of leakage is presented. Its low cost, high injectivity capacity and low density of the hydrated product (hydrogel) makes this technique attractive. The solgel synthesis was optimized for (1) reducing energetic and material costs; (2) improving the chemical and mechanical properties of the emplaced product and (3) controlling the duration of the aging process in order to form a solid hydrogel after a few days. Permeability tests that consisted of injecting the synthesized solgel in different porous media confirmed the sealant capacity of the emplaced hydrogel to significantly reduce rock permeability.
\end{abstract}

Keywords: solgel; remediation of leaky reservoirs; underground $\mathrm{CO}_{2}$ storage

\section{Introduction}

Confinement failure is recognized as a critical event that can compromise the success of the underground storage of $\mathrm{CO}_{2}$ in permeable sedimentary reservoirs such as sandstones and limestones. Leakage risks concern, in the first instance, the reservoir caprocks and wellbore cements that can both be damaged because of natural or anthropogenic (hydro-)mechanical events [1]. New preferential pathways in the caprock, such as fractures, can occur during the injection, caused, for instance, by over pressure or during the repository period due to tectonic events or unexpected spreading of the $\mathrm{CO}_{2}$ out of the targeted area [2-4]. Unidentified preexisting fractures in the caprock represent also a risk that must be taken into account. Conversely, well completion represents a potential direct pathway to overlaying aquifers and surface environment and is identified as a main risk of confinement failure [5]. Fractures in the cement annulus as well as breakdown at the caprock-cement interface and at the cement-casing interface may grow during $\mathrm{CO}_{2}$ injection as a result of pressure and thermal changes. Leakages can occur at the caprock-cement interface, at the cement-casing interface, through the cement annulus itself or through the cement plug in the case of abandoned wells [5,6].

While regulations should aim to faultless $\mathrm{CO}_{2}$ storage operation, it is obvious that errors may occur and operators should include actions to mitigate the possible accidents, considering specifically 
defaults of confinements that produce leakage of the stored $\mathrm{CO}_{2}$ or reservoir brine [7-9]. Leakage issues are manifold [10]. In addition to the difficulties related to detecting leakages [11], the primary action in case of leakage should be to stop the injection in order to stabilize the reservoir pressure and to dissipate local over pressure. Pumping back the reservoir fluid is also a recommendable action [12]. To be effective, the system must be anticipated during the well and surface infrastructures construction. Another type of action concerns the treatment of the effluent in case of leakage. All these proceedings are highly demanding in terms of equipment, expertise and cost but the concepts are known and the technologies do exist. Additionally, remediation technologies for rebuilding the sealing capacity of the degraded material or adding a new sealing layer are often mentioned as part of the risk mitigation procedures required for underground $\mathrm{CO}_{2}$ storage [11]. Restoring the sealing capacity of a leaky reservoir is obviously the most advantageous action but it is a highly challenging task and, currently, the portfolio of leakage remediation methods is scarce. Such remediation process implies the injection of a liquid material into porous or fractured geo-materials. This issue concerns the accessibility to the leaky zone, specifically in the case of a localized leakage in the caprock, such as a fracture. For instance, drilling new boreholes to intercept a fracture in the caprock is both highly expense and very challenging in term of technology. Yet, this would be required if a massive leakage endangers strategic aquifers or surface environmental and economic stability. Restoring the sealing capacity of a leaky (injection, monitoring or abandoned) well is evidently less challenging. In both cases the success of the remediation procedure will rely on the use of the appropriate sealant material.

Sealant material requires specific chemical and mechanical properties such as suitable low viscosity to enable injection, controllable setting properties as well as chemical and mechanical stability of the emplaced material. Currently, (engineered) Portland cement injection is the only industrial technique available but alternative mineral, organic or biologic products are currently investigated with variable success. The potential application of some of these techniques depends strongly on the location and severity of the leakage. The viscosity of the injected material is a critical parameter that will influence the nature of the remediation scenario. High viscosity materials, such as Portland cement, can be used to seal large discontinuities connected to the well. The procedures for remediating a localized leakage zone in a well by injecting Portland-type cement in-between packer is known from decades of use in the oil industry. Yet, it is a challenging task that furthermore requires stopping the production. Although some researchers have attempted to mitigate the limitations of conventional Portland cement during years $[5,13,14]$, it is obvious that it still displays some identified weaknesses, such as its limited ability to penetrate into the formation matrix for distances larger than a few inches, shortcomings during setting into water or gas saturated gaps and a lack of chemical resistance to $\mathrm{CO}_{2}$-rich water over significant periods of time $[15,16]$.

At the same time, new technologies have been investigated for replacing or complementing classical Portland cement practices (it is worth noting that, technically speaking, Portland cement is a geopolymer). Geopolymers, and specifically Al-Si geopolymers, display appealing advantages to replace Portland cement in the well: higher strength of the aged material, better volume stability as well as better durability and resistance to acids $[2,17,18]$. However, geopolymers display viscosity values similar to Portland cement and thus present the same limitations as Portland-type cements in terms of application.

An interesting way of reducing porosity and permeability is to promote the growth of biofilms [19]. It is worth mentioning that this technique has been previously investigated for enhanced oil recovery (with poor results) for increasing the mobility and the relative permeability of oil. The property targeted for leakage mitigation objectives is the capacity of specific microorganisms to produce carbonate minerals in situ $[20,21]$. The idea here is that carbonate minerals would remain in the porosity, reducing permeability even after any biofilm decay which was the limitation of this technique. The injection of the biomass precursor and biomass nutriment for mitigation of $\mathrm{CO}_{2}$-rich brine leakage faces several difficulties, such as the tremendous variability of the biomass processes in natural environments triggered by the extreme sensitivity of the biomass functionalities to chemical and 
physical conditions that are poorly controllable and unpredictable over the typical values of the storage duration. Foams and aqueous gels (silica-based gels) have been investigated for decades as potential techniques for decreasing the permeability of preferential flow paths. Foam potential has been recently improved thanks to the possibility of combining this practice with nanotechnology that could lead to improved stability of the foam [22-25]. Several types of polymer-based gels and, in particular, silicate gels have been proposed as possible candidates for reducing porous media permeability [26,27]. The low viscosity of initial silicate fluids before polymerization is clearly a remarkable property for improving the product penetration into small size pores, fissures and debounded interfaces. Moreover, silicate gels usually show good thermal and chemical stability, and they are low cost and environmental friendly materials that can be quite easily removed in case of unexpected deployment failure $[2,28]$. Combination of silicate gels and bacteria is another breakthrough procedure. Interesting results have been obtained for repair cracks in concrete under surface conditions. Specific bacteria growing in the solgel matrix, that act as both nutriment and cation precursor, are able to promote the precipitation of carbonate minerals in their cell walls enhancing the durability of the emplaced material [29]. The application to reservoir conditions will require more research and will probably face the same difficulties concerning the sensitivity of the biomass functionalities to chemical and physical conditions that those mentioned above when discussing the use of biofilms. Leakage remediation approaches using a combination of techniques were also investigated. For instance, some researchers proposed a potential injection scenario composed of a first cement injection to create a barrier to mitigate the differential pressure followed by a secondary injection of a gel to create a chemically stable sealing agent exposed to $\mathrm{CO}_{2}$ [30]. This quick overview shows that scientists are investigating a large range of options in response to the identified need of proposing solution for leakage remediation, but today these technologies are not mature for industrial application to underground $\mathrm{CO}_{2}$ storage.

In the context of underground $\mathrm{CO}_{2}$ storage, the use of silicate sealant materials seems to be an attractive solution because of the low reactivity of silicate in carbonate-rich brine [31,32]. The critical issue that has not been solved so far is to reach sufficiently high concentration of $\mathrm{Si}$ in the low viscosity fluid to be injected, so that the solidified material, after aging, fill a high fraction of the porosity while displaying a high mechanical strength. This condition excludes the use of aqueous solution of $\mathrm{Si}$ because of the low solubility of Si even in the most favorable conditions of temperature and $\mathrm{pH}$. These properties must be obtained together with other constraints such as the resistance to acidic organic and inorganic fluids and to the presence of biomass, and the need of controlling the duration of the solidification process depending on the local condition (i.e., pressure and temperature). The cost effectiveness of the product as well as the need to comply with the procedures and equipment used in oil and gas industry are additional key issues.

In this paper, the main results of a study aimed at developing a new sealant product based on an organic silica precursor associated with a solgel process are reported. The objective of this work was not only to produce an alternative or a complement to Portland cement for treating leaky well completion, but also to propose a product that displays sufficiently low viscosity (1) for penetrating fissured materials and the zones of debonding at the interface between the well cement annulus and the caprock and (2) for massive injection in the reservoir at the end of the injection period as a preventive procedure to avoid the $\mathrm{CO}_{2}$-rich brine staying in contact with the injection zone of the well. The study of the organic silica gel chemistry is not a new approach-it was in early 1845 that the French chemist Ebelmen reported for the first time that the metal alkoxide synthesized from $\mathrm{SiCl}_{4}$ and alcohol became gel on exposure to the atmosphere [33,34]. Nowadays, the so-called solgel technique is a powerful method for obtaining high performant glass materials such as hybrid substances and nanocomposites for optic, electronic, metallurgic, stone consolidation and nuclear fields [34-36], but it should be adequately adjusted in order to create a proper product for leakage remediation in underground reservoirs. 


\section{Materials and Methods}

\subsection{Solgel Chemistry and Synthesis}

The synthesis of a solgel can be carried out by destabilization of a colloidal solution obtained from metal salts in aqueous solution or by polymerization of molecular species obtained by metal alkoxides $(\mathrm{M}(\mathrm{OR}) \mathrm{n}$, where $\mathrm{M}$ is a metal with oxidation degree $\mathrm{n}$ and $\mathrm{OR}$ is an alkoxy group) in organic solutions [35,37]. In this work, the polymerization method was used, that develops in two stages (hydrolysis and condensation), and a silicon alkoxide $\left(\mathrm{Si}(\mathrm{OR})_{4}\right)$ as a precursor. After testing two different solgel precursors (TEOS and ETS40 based sols), it was decided to work with ETS40 which showed similar results to TEOS for this specific application, but could be synthesized in large quantities for a small fraction of the cost.

The key chemical reactions involved in the solgel synthesis are described in Figure 1a. In short, water hydrolyzes a fraction of the ethoxy groups $\left(-\mathrm{OC}_{2} \mathrm{H}_{5}\right)$ present in ETS40 to create silanol groups (Si-OH) (reaction 1.1 in Figure 1a). Thereafter, as soon as a silanol group is formed, it reacts with either an ethoxy group (reaction 1.2) or another silanol group (reaction 1.3) to create siloxane bonds (Si-O-Si) which provide the solgel with its specific properties. Note that reactions 1.2 and 1.3 are condensation reactions that produce alcohol and water, respectively.

The procedure followed to synthesize the solgel was based on that described in [38]. The authors synthesized a solgel by hydrolyzing TEOS based sol in presence of hydrochloric acid in a water/ethanol solution for $3 \mathrm{~h}$ at $40{ }^{\circ} \mathrm{C}$ under stirring. In this case, TEOS-based sol was replaced by ETS40-based sol. Given that silicon alkoxides are not miscible in water, a co-solvent (in this case, the ethanol) is usually used to carry out the reaction. In addition, a catalyst agent (an acid or a base) is added to the solution, since silicon alkoxide hydrolysis is noticeably slow in pure water. Depending on the nature of the catalyst that it is used, the solgel obtained could be distinctly different. An acid $\mathrm{pH}$ accelerates hydrolysis and slows down condensation, whereas a basic $\mathrm{pH}$ promotes the opposite situation. Thus, an acid $\mathrm{pH}$ favors network development yielding a polymeric solution (polymeric solgel), while a basic $\mathrm{pH}$ favors nucleation leading to a colloidal solution (colloidal solgel).

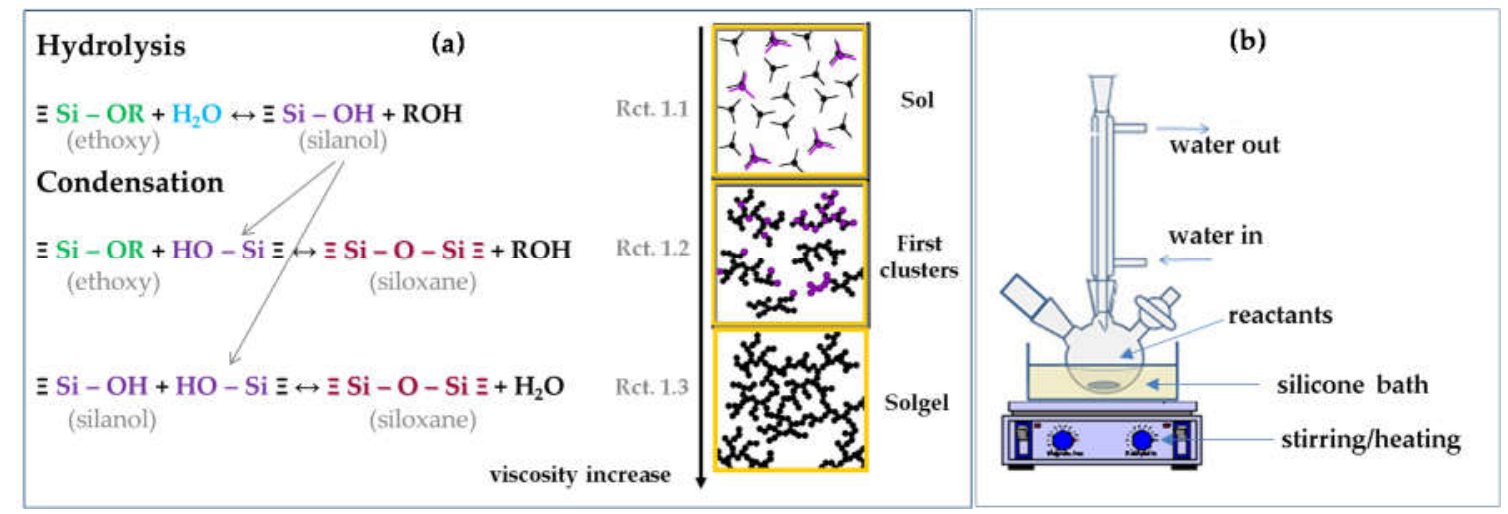

Figure 1. (a) Reactional mechanism of transformation of ETS40-based sol in solgel; (b) Experimental setup to run solgel synthesis. Rct. = reaction.

The solgel was synthesized at laboratory scale, in temperature-controlled conditions, using the stirred system displayed in Figure 1b. Then, the liquid-synthesized solgel was aged; first, it became a hydrogel and eventually a glass. The transformation to glass can be avoided if the hydrogel is kept in closed systems or in water-saturated conditions.

\subsection{Permeability Tests}

In order to assess the sealant capacity of the synthesized solgel, two sets of permeability tests were performed in reservoir rock samples. 
The first set of experiments consisted of injecting the synthesized solgel into cores $(9 \mathrm{~mm}$ diameter $\times 18 \mathrm{~mm}$ length) of a porous reefal carbonate (limestone) reservoir (Mallorca, Spain), and measuring air permeability before and after solgel injection. The carbonate core samples had a connected porosity of $\approx 30 \%$ and an initial air permeability of $\approx 150 \mathrm{mD}\left(k_{a 0} \approx 150 \mathrm{mD}\right)$. More details of sample properties can be found in $[39,40]$. The experimental setup used to inject the synthesized solgel in the porous sample is presented in Figure 2a. Before solgel injection, the core was either vacuumed (valve VALV-VAC open and valve VALV-SYR closed) or water-saturated in order to evaluate the influence of the water saturation on the emplacement of the solgel and on the induced permeability decrease. Thereafter, a volume of $10 \mathrm{~mL}$ of the synthesized solgel was introduced in the syringe and VALV-SYR and VALV-VAC were opened, allowing the solgel to fill the pore space of the core sample. For the vacuumed sample case, the solgel was sucked into the core by the vacuum. For the water-saturated sample case, first the sample was saturated (using vacuum) with dyed water (thermodynamically equilibrated with the rock-forming minerals) and then the solgel was injected at a pressure of $\sim 0.3 \mathrm{MPa}$ using the syringe. Note that it was important to leave the experimental setup in vertical position to let air bubbles to go up after solgel injection. Once the solgel was injected in the porous samples it was not possible to visually determine the aging of the solgel inside the pores. Therefore, a closed flask with some milliliters of solgel was left aside and it was used as a reference (REF) to control the solgel gelation and solidification time.

(a)

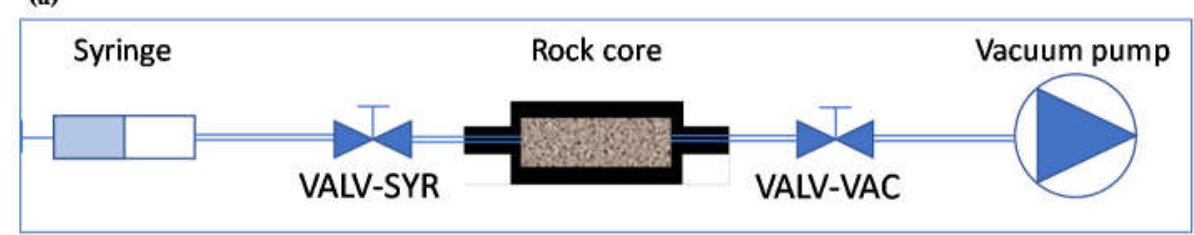

(b)

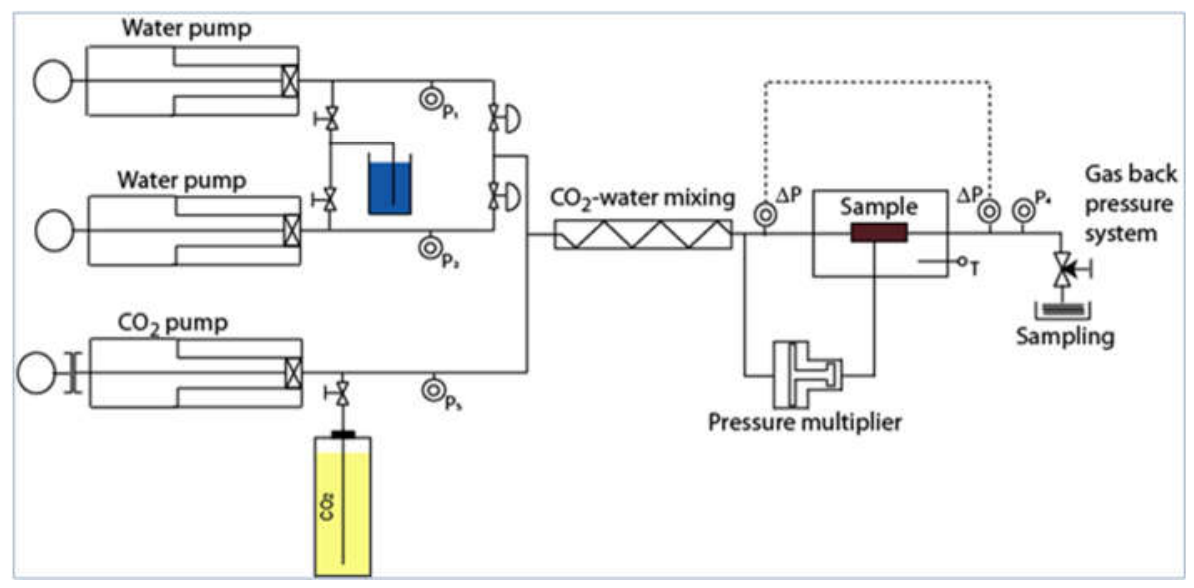

Figure 2. (a) Experimental setup for solgel injection in a porous rock sample. VALV-SYR corresponds to the valve that connects the syringe to the rock core, and VALV-VAC indicates the valve that connects the rock core to the vacuum pump. A heat-shrinkable sheath maintains the two valves linked to the rock sample and allows vacuum conditions in the system; (b) Schematic representation of the Icare Lab 1 flow-through system used to measure water permeability of the porous samples before and after solgel injection.

In the first set, for each sample, air permeability measurements were run at different times of the solgel aging and then the resulting permeability values were compared with the initial permeability $\left(k_{a 0}\right)$ implementing the following procedure: 
Once solgel was injected in the core samples, the first air permeability measurement was performed when solgel became hydrogel in the reference flask $\left(k_{a g}\right)$. Thereafter, samples were aged differently following the protocol schematized in Figure 3.

(1) the reference flask was opened, promoting hydrogel solidification, and the corresponding rock permeability $\left(k_{a s}\right)$ was measured when the hydrogel became glass in the flask.

(2) the core sample was immersed in water during some time (few days). After this time, either (2.1) the core was put out of the water and rock permeability $\left(k_{\text {agw }}\right)$ was immediately measured or $(2.2)$ the core was put out of the water, the reference flask was opened, and rock permeability $\left(k_{a s w}\right)$ was measured when the hydrogel became glass in the reference flask.

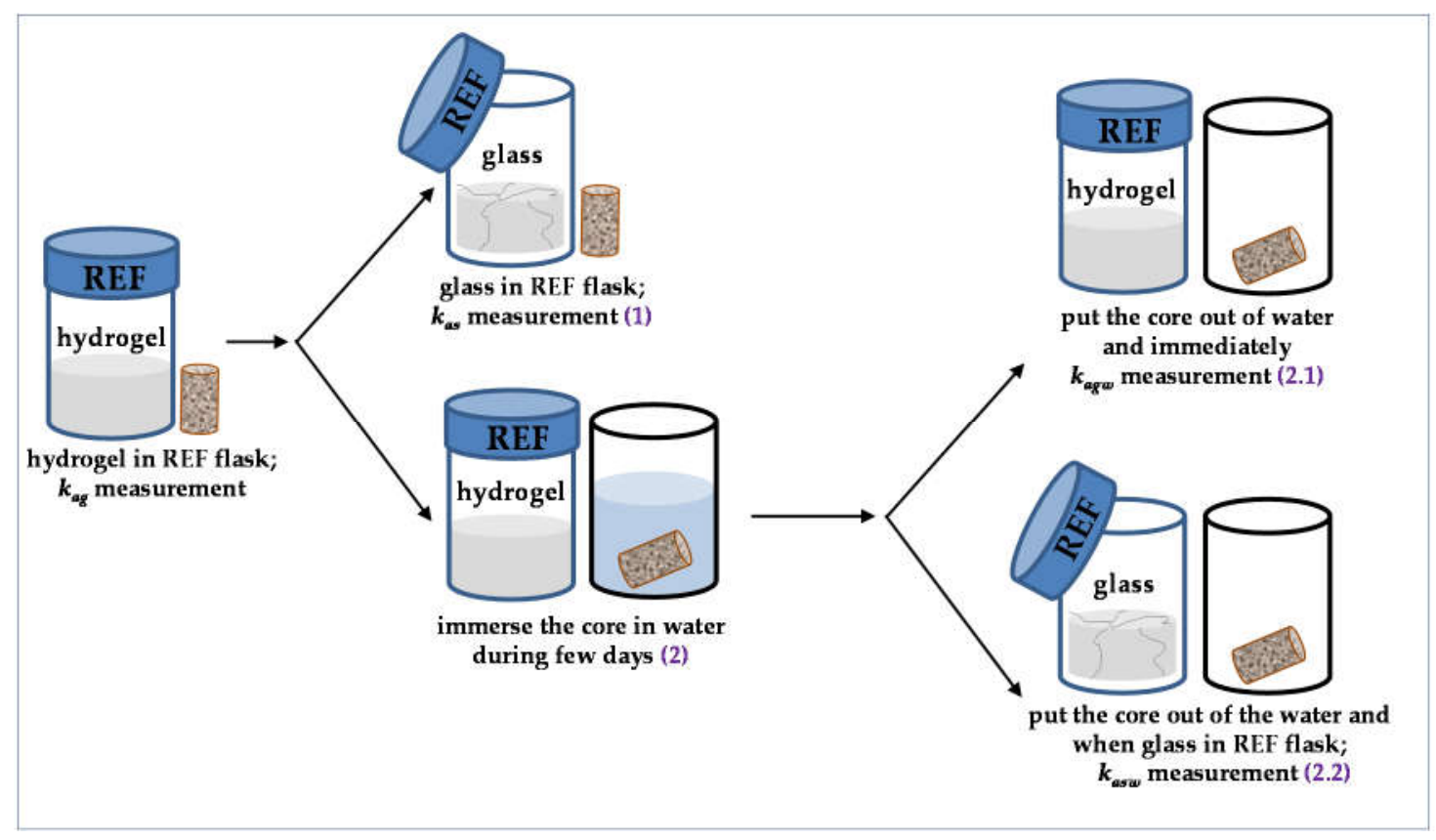

Figure 3. Scheme of the different air permeability measurements performed in the first set of experiments. Values of $k_{a g}$ and $k_{a g w}$ were measured when solgel inside the porous cores became hydrogel whereas $k_{a s}$ and $k_{a s w}$ values were measured when the hydrogel inside the porous cores became glass. The reference flask (REF) was used to determine the time required for the solgel to become hydrogel and eventually glass.

Permeability was evaluated using an air permeameter, Top Industrie 2706. This technique is a non-invasive method that consists of injecting dry nitrogen at different controlled flow rates and measuring the pressure drop over the samples. The air permeability of each sample was computed using at least 4 pairs of pressure-drop/flow-rate ratios and applying the Darcy's law modified for taking into account gas compressibility (assuming perfect gas behavior) [41]:

$$
Q=k_{a} \times S \times \frac{\left(P_{1}^{2}-P_{2}^{2}\right)}{\left(2 \times \mu \times P_{2} \times L\right)}
$$

where $Q$ is the flow rate in $\mathrm{m}^{3} \cdot \mathrm{s}^{-1}, S$ is the cross section in $\mathrm{m}^{2}, k_{a}$ is the air permeability in $\mathrm{m}^{2}, P_{1}$ and $P_{2}$ denotes the inlet and the outlet pressure in Pa, respectively, $\mu$ is the dynamic viscosity in $\mathrm{Pa} \cdot \mathrm{s}$, and $L$ is the sample length in $\mathrm{m}$. Note that the value of permeability measured using this technique required to be further corrected from gas slippage effect (Klinkenberg correction [42]). However, this correction was not applied here because the aim was not to measure the true permeability but to evaluate the change of permeability caused by solgel injection. 
The second set of experiments was carried out similarly to the first set, but permeability was measured using a water permeameter allowing us to reproduce the water-saturated environment and the pressure-temperature conditions expected for a leakage in an injection well (12 MPa and $40{ }^{\circ} \mathrm{C}$ ). Here, two types of reservoir rock were used: the same reefal carbonate from Mallorca (Spain) used during the first set of experiments, and samples of Berea sandstone. Initial water permeability of the core samples ( $9 \mathrm{~mm}$ diameter $\times 18 \mathrm{~mm}$ length) before solgel injection $\left(k_{0}\right)$ was of $\approx 45 \mathrm{mD}$ for the carbonate samples and of $\approx 3.5 \mathrm{mD}$ for the sandstone samples. Once solgel was injected in the porous sample using the experimental setup shown in Figure 2a and it became hydrogel inside the pores (hydrogel formation controlled using the reference flask) water permeability was measured again $\left(k_{g}\right)$. Permeability was measured using the Icare Lab 1 flow-through system (Figure $2 b$ ), which belongs to the Géosciences department of the CNRS (Montpellier, France). Details concerning this equipment can be found in [43]. The injected aqueous solution used to measure permeability was a rock-equilibrated brine, in order to avoid any permeability changes due to chemical reactions. The rock-equilibrated brine was injected into the percolation cell (where the core sample was installed into a silicon jacket) by a motorized piston-pump system at reservoir conditions $\left(P=12 \mathrm{MPa}\right.$ and $\left.T=40^{\circ} \mathrm{C}\right)$ and constant flow rate. The system was equipped with displacement encoders that allowed the accurate control of the flow rate from 0.005 to $5 \mathrm{~mL} \cdot \mathrm{min}^{-1}$. Radial confining pressure equal to $112 \%$ of the inlet pressure was applied to the silicon jacket that covered the sample. The piston pump motion and the pneumatically-controlled valves were operated by LabView-based software. Experiments were run in water-saturated samples (water thermodynamically equilibrated with the rock-forming minerals) in order to better mimic the conditions of the final solgel emplacement.

\section{Results and Discussion}

\subsection{Key-Parameters Controlling Solgel Applicability}

Different tests using the liquid-synthesized solgel were performed in order to characterize the solgel aging process, i.e., the formation of a gel followed by the gel solidification. The procedure for the aging tests was as explained hereafter. First, some milliliters of the synthesized solgel were poured in flasks and aged in different ways at atmospheric pressure $(P)$ and room temperature $(T):(1)$ in an open flask, (2) in a closed flask, and (3) in a closed flask with the addition of some milliliters of water that stayed by gravity on the top of the solgel reproducing the interface between the solgel and the pore water contained in reservoir conditions. A second set of aging experiments was performed at $P-T$ representative of underground storage conditions. Based on the results obtained from the different aging tests, the solgel synthesis was modified in order to improve solgel properties in relation to the objectives in terms of injectivity and final product characteristics after emplacement.

Solgel aging, at atmospheric $P$ and room $T$, in open flasks (open system) enabled ethanol (EtOH) and water (W) evaporation and led to the formation of a xerogel and eventually a solid glass with noticeable shrinking whereas aging the solgel either in a closed flask or in a closed flask in contact with water, that mimic reservoir conditions, led to the formation of a hydrated gel (hydrogel) with no fissures and no shrinking (Figure 4a). In the latter case, the viscosity of the solgel increased gradually while the solgel polymerized until becoming a rigid material. Its stiffness can be observed in Figure 5. Shrinking effect was evaluated from volumetric measurement. Note that shrinking was always associated with visible cracks. The aging tests indicated that the applicability of solgel as a sealing agent depends on the aging process. The obtained rigid hydrogel seemed to display the required properties for being used as a sealant agent.

Variations in $P$ and $T$ during the aging process did not change the final properties of the material but modified the times to form gel and solid. An increase in $T$ brought forward the time to form gel, while no measurable effect was observed when changing $P$. Clearly, the temperature of the targeted location for the solgel emplacement is a critical parameter that must be taken into account to optimize the product formulation. 
The parameters of the solgel synthesis were modified, aimed at (a) improving the properties of the final product, and (b) minimizing the related costs.

After testing different adjuvants $\left(\mathrm{C}_{12} \mathrm{H}_{28} \mathrm{O}_{4} \mathrm{Ti}, \mathrm{B}_{2} \mathrm{O}, \mathrm{Ta}_{2} \mathrm{O}_{3}\right.$, etc.), boron oxide $\left(\mathrm{B}_{2} \mathrm{O}_{3}\right)$ was introduced as a reactant to the solgel synthesis in order to improve the mechanical strength of the resulting material.
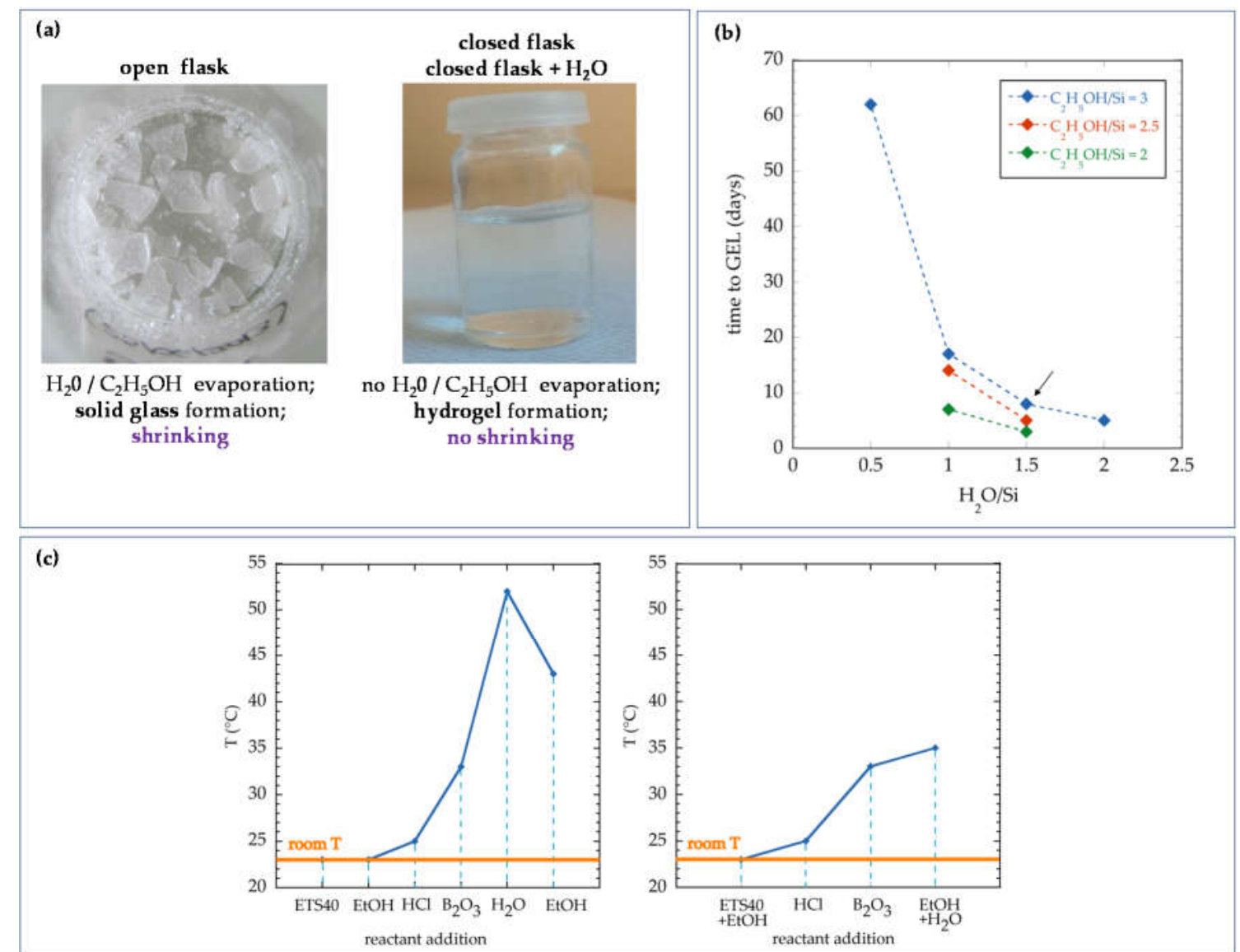

Figure 4. (a) Drying tests results (controlling solgel applicability); (b) time to form gel (in days) versus the $\mathrm{H}_{2} \mathrm{O} / \mathrm{Si}$ ratio used in the solgel synthesis for solgels produced with an EtOH/Si ratio of 3 (in blue), 2.5 (in orange) and 2 (in green); (c) monitoring of temperature during the addition of reactants to the bulk solution in the solgel synthesis. Note that the black arrow in (b) indicates the best solgel in terms of gel formation time, viscosity and reactivity selected to perform the permeability tests.

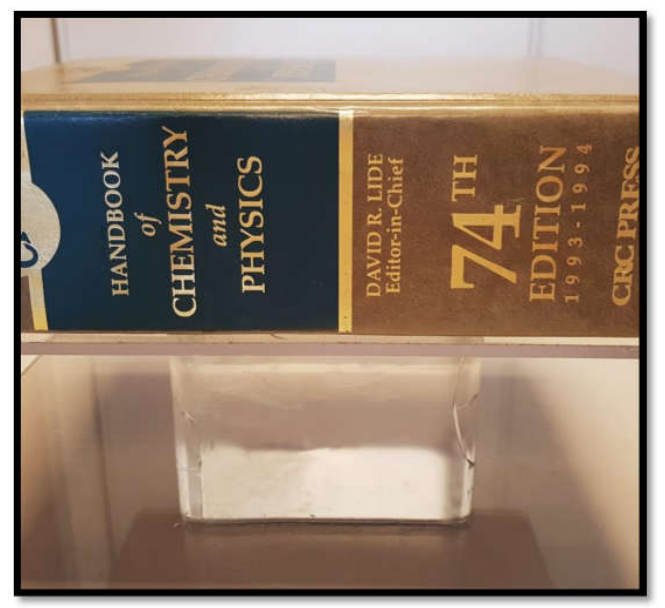

Figure 5. A $25 \times 20 \times 20 \mathrm{~cm}^{3}$-hydrogel block overlaid by a $3.2 \mathrm{~kg}$ weight (corresponding pressure of $10^{-3} \mathrm{MPa}$ ). 
Given that using the initially proposed procedure to synthesize solgel some water/ethanol mixture was expulsed during aging and it remained on the gel surface, different $\mathrm{EtOH} / \mathrm{Si}$ and W/Si ratios were tested. The target was keeping viscosity low and producing a solgel that became hydrogel in 4 to 8 days that was considered the appropriate duration for the emplacement procedure at industrial scale. The EtOH/Si and W/Si ratios initially used, following the published procedure, were both equal to 4. According to Klein, 1985 [44], solgel viscosity is directly related to the EtOH/Si ratio. Different experiments were run varying this ratio from 4 to 1 . Results showed that solgel was suitable for injection (sufficiently low viscosity) if the $\mathrm{EtOH} / \mathrm{Si}$ ratio used in the synthesis was $\geq 2$. Additionally, different W/Si ratios were tested (from 4 to 0.5). Experimental results showed that the duration to form the hydrogel was strongly controlled by the W/Si ratio. Figure $4 \mathrm{~b}$ shows that the higher the amount of water used in the synthesis the shorter the hydrogel formation time. Only little effects on the viscosity were noticed for the range of $\mathrm{W} / \mathrm{Si}$ ratio used.

Altogether, the analysis of the results indicated that a solgel with an $\mathrm{EtOH} / \mathrm{Si}$ ratio equal to 3 and a W/Si ratio equal to 1.5 (indicated with a back arrow in Figure $4 \mathrm{~b}$ ) was the optimal option corresponding to a low viscosity solgel that formed hydrogel in 8 days. For these conditions, no residual water/ethanol mixture was observed on the hydrogel surface. A solgel, synthesized using these ratios, was used to run the permeability tests discussed in Section 3.2.

The temperature used in the solgel synthesis was found to be a key parameter that highly influenced the properties of the final product. Initially, and based on solgel synthesis information found in the literature [38], solgel synthesis was performed at $40^{\circ} \mathrm{C}$. However, most of the reactions involved in the synthesis are exothermic. Accordingly, different tests were performed varying the temperature used in the synthesis and evaluating the properties of the resulting solgels such as viscosity, time to form gel, etc. Results showed that if the temperature of the bulk solution was maintained between 20 and $40{ }^{\circ} \mathrm{C}$, the time to form gel and the viscosity of the resulting solgels were similar and appropriate. However, if the temperature exceeded the $45^{\circ} \mathrm{C}$, the time to form gel was appreciably shorter than the previous one (in some cases, less than one day) and the viscosity of the solgels obtained was too high. Therefore, the temperature of the synthesis was set to $20^{\circ} \mathrm{C}$ preventing the heating of the mixture during the synthesis and promoting an important energy and cost reduction.

On the other hand, it was noticed that if the amount of water, responsible for the hydrolysis, was added to the bulk solution at the same time that the ethanol (co-solvent), the temperature remained low (less than $35^{\circ} \mathrm{C}$ ) (Figure 4c-right), contrarily to the significant change in $T$ obtained in the case that water and alcohol were added separately ( $T$ increased up to $52{ }^{\circ} \mathrm{C}$ ) (Figure 4c-left). The azeotrope water-alcohol mixture was probably influencing $T$ changes during reaction. Taking into account that heat dissipation should be much less efficient when producing the large quantities required for industrial application it is important to reduce the exothermic nature of the reaction by following the right order when mixing the reactants.

\subsection{Sealant Capacity of the Hydrated Gel}

Based on the results obtained in the aging tests discussed above where solgel (as hydrated gel) was found to be a priori suitable for being used as a sealant agent, a series of permeability tests were conducted to evaluate the sealant capacity of this product. Two sets of experiments were performed that consisted of injecting the synthesized solgel into porous rock cores and then measuring either air permeability (first set) or water permeability (second set).

\subsubsection{Air Permeability Tests}

Air permeability results obtained from solgel injection tests carried out with the reefal carbonate samples are displayed in Figure 6. A noticeable reduction of the core permeability (from $k_{a 0}=150 \mathrm{mD}$ to $k_{a g} \approx k_{\text {agw }} \approx 0.5 \mathrm{mD}$ ) was achieved in experiments where solgel remained hydrogel inside the porous rock. This situation occurs when the aging conditions prevent evaporation and consequently shrinking of the product, i.e., when the solgel-filled core dries in closed systems as well as when it is immersed 
in water (up to 250 days). These results indicate that the injection of the solgel in a reservoir, which is supposed to be initially water saturated, satisfies the specifications, regarding injectivity and pore filling, for being an appropriate sealant product for leakage remediation. In contrast, shrinking will reduce the efficiency of the product if glass formation by drying occurs; in these cases, the measured reduction of permeability was not significant (from $k_{a 0}=150 \mathrm{mD}$ to $k_{a s} \approx 60 \mathrm{mD}$ and $k_{a s w} \approx 30 \mathrm{mD}$ ). Desaturation of the treated zone is clearly a factor that can compromise the sealing capacity of the product.

Albeit air permeability tests shown in Figure 6 were primarily performed using a solgel synthesized with $\mathrm{EtOH} / \mathrm{Si}=3$ and $\mathrm{W} / \mathrm{Si}=1.5$, some experiments were run varying both these ratios to analyze their influence in permeability. Indeed, experiments ran with the same W/Si ratio presented similar slope $(\gamma)$ of permeability decrease, and the higher the W/Si ratio the higher the slope (Figure 7a). These results revealed the expected influence of the amount of the water content on the solidification process (water condensation): more water content in the solgel implies more shrinking of the product as it solidifies and, as a consequence, less capacity to completely fill pores or fractures in a reservoir.

(a)

\begin{tabular}{|c|c|c|c|c|c|c|c|c|}
\hline \multirow{2}{*}{ Rock sample } & \multicolumn{8}{|c|}{ Permeability $(\mathrm{mD})$} \\
\hline & $k_{a \theta}$ & $k_{e g}$ & & $k_{\text {egre }}$ & (days) & & $k_{a s}$ & $k_{\text {asp }}$ \\
\hline Carbonate M4 & 145.3 & - & $\cdot$ & - & - & - & 57.4 & $\cdot$ \\
\hline Carbonate M13 & 137.6 & - & - & - & - & - & 51.2 & - \\
\hline Carbonate M16 & 138.3 & - & - & - & - & - & 68.9 & - \\
\hline Carbonate M18 & 72.7 & - & - & - & - & - & 29 & - \\
\hline Carbonate M20 & 144.6 & 0.3 & - & - & . & - & 70.7 & - \\
\hline Carbonate MI9 & 135.9 & 0.5 & $3.2(24)$ & $0.6(41)$ & $1.0(179)$ & - & - & 19.4 \\
\hline Carbonate $\mathrm{M} 22$ & 96.6 & 5.3 & $0.7(20)$ & $0.3(37)$ & $1.1(175)$ & - & - & 13.7 \\
\hline Carbonate M21 & 139.1 & 0.2 & $0.4(15)$ & $0.2(31)$ & $0.2(222)$ & ongoing & - & ongoing \\
\hline Carbonate M24 & 146.7 & 0.7 & $1.2(20)$ & - & . & . & - & 21.5 \\
\hline Carbonate $\mathrm{M} 23$ & 160.7 & 1.7 & $0.8(20)$ & - & - & - & - & 38.0 \\
\hline Saturated carbonate $\mathrm{M} 33$ & 162.46 & 0.1 & - & - & - & - & 76.3 & - \\
\hline Saturated carbonate M30 & 155.01 & 0.3 & $0.2(42)$ & $0.3(250)$ & - & - & - & 35.2 \\
\hline Saturated carbonate $\mathrm{M} 31$ & 157.9 & 0.2 & $0.2(41)$ & $0.4(250)$ & - & - & - & 29.6 \\
\hline Saturated carbonate M32 & 146.2 & 0.2 & $0.4(37)$ & $1.1(250)$ & - & - & - & 38.5 \\
\hline
\end{tabular}

(b)

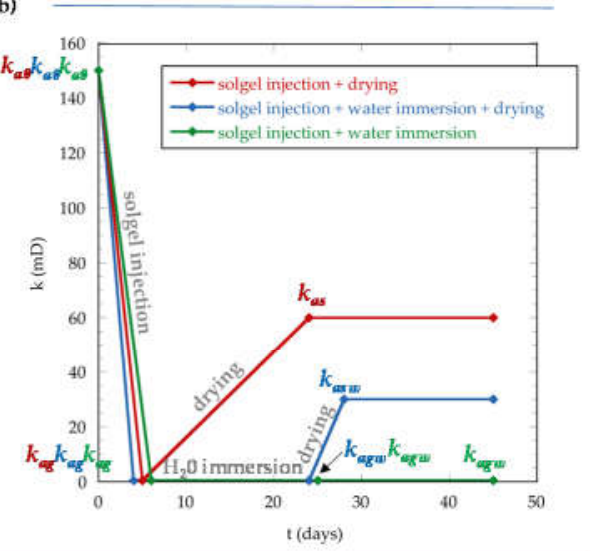

$k_{\alpha \theta}=$ initial air permeability.

$k_{\text {ag }}=$ air permeability when solgel in the pores is hydrogel.

$k_{a s}=$ air permeability when solgel in the pores is glass.

$k_{\text {agw }}=$ air permeability, after water immersion, when solgel in the pores is hydrogel.

$k_{\text {asw }}=$ air permeability, after water immersion, when solgel in the pores is glass.

Figure 6. (a) Experimental results of the air permeability tests performed with vacuumed and water-saturated reefal carbonate samples; (b) scheme showing the experimental results presented in (a). $k_{a 0}$ indicates initial permeability before solgel injection; $k_{a g}$ and $k_{a g w}$ denote permeability values measured when solgel inside the porous cores was hydrogel whereas $k_{a s}$ and $k_{a s w}$ show permeability values measured when solgel inside the porous cores was glass. $k_{a g w}$ and $k_{a s w}$ values correspond to the permeability measured in samples that were immersed in water before the permeability measurement. Note that the values in brackets shown in the Table indicate the number of days that the core sample was immersed in water before the permeability measurement.

For some experiments, changes in core permeability were monitored during solgel transformation from hydrogel to glass (values from $k_{a g w}$ to $k_{a s w}$ in Figure $7 \mathrm{~b}$ ). Such tests were performed in samples where first, solgel was injected and it became hydrogel inside the pores, second, samples were immersed in water during some period of time, and third, samples were taken out of the water and permeability measurements were performed during the transformation from hydrogel to glass. The drying of the hydrogel inside the pores lasted less than 2 days in both the cases displayed in Figure $7 \mathrm{~b}$. In the first $24 \mathrm{~h}$, air permeability continuously increased up to reach a steady value of $30 \mathrm{mD}$, approximately. Note that the permeability increase was always slightly less significant when the rock core was previously immersed in water ( $k_{a s w} \approx 30 \mathrm{mD}$ compared to $k_{a s} \approx 60 \mathrm{mD}$ ) (Figure $6 \mathrm{~b}$ ). This fact seemed to be related with a possible increase of the solgel volume (which was already hydrogel) when it was in contact with water by permitting that reactions responsible to hydrogel formation continued 
if more water was available in the system. The presence of excess water triggering a further hydration of the hydrogel up to the maximum $\mathrm{H}_{2} \mathrm{O}$ molecules allowed by the siloxane polymerized structure. This fact supported the use of this product as a sealant agent in water containing reservoirs.
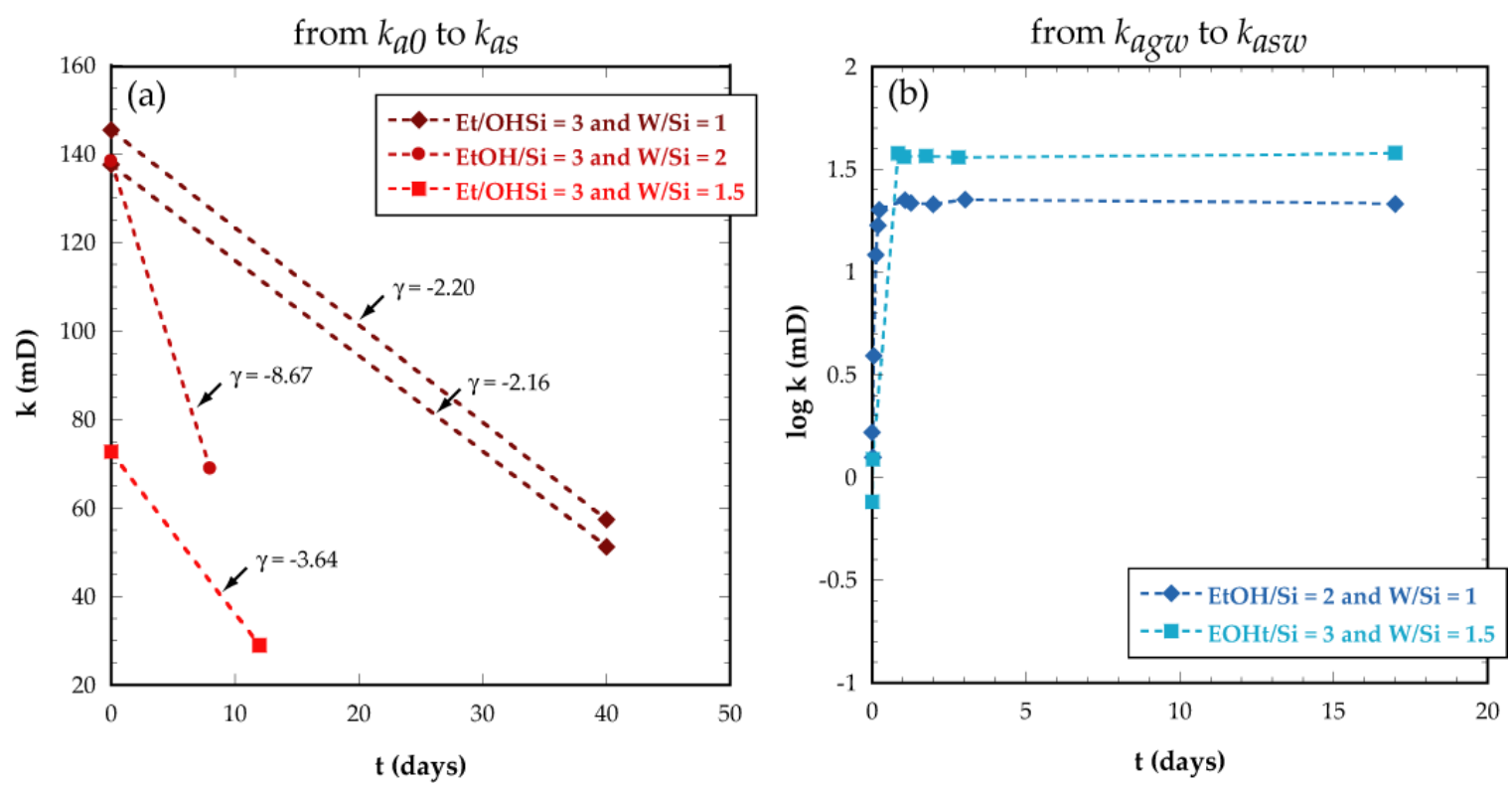

Figure 7. (a) Air permeability decrease as a function of the W/Si ratio; (b) Variation in air permeability during hydrogel drying for two hydrogel-filled cores immersed in water during 20 days. The values of the slope $(\gamma)$ are indicated in Figure 7a.

The same air permeability tests presented in Figure 3 were run with carbonate cores that were saturated with a carbonate-equilibrium solution before solgel injection, to better reproduce the real conditions corresponding to injecting the solgel into a reservoir at depth. The experimental results obtained were practically the same as those obtained with the initially vacuumed samples (Figure 6a). This suggests that when solgel was injected into the water-saturated core samples, it efficiently flushed the pore water. The wettability of the synthetized solgel (compared to that of water) in these types of rocks was not measured, however it was observed that the (wetting) meniscus of the freshly prepared solgel in the glass flasks was more marked than that of the control flasks containing water at room pressure and temperature. Extrapolation to the rock-forming minerals and higher temperature values would require more accurate appraisal, but these indirect indications suggest that the solgel is at least as wetting as water. Moreover, albeit clear that the solgel efficiently saturated the previously water-saturated pores, it cannot be excluded that some residual water volumes may be trapped as isolated clusters in the porosity dead ends. These confined water volumes will participate to maintaining the hydrogel water-saturated and therefore are beneficial for the process.

The results of this first set of experiments ascertained the efficiency of solgel (when emplaced as a hydrogel phase) for leakage remediation. Yet, it is worth noting that air permeability measurement is not the most recommended method for investigating hydrogel-saturated samples, even though the method is rapid. Indeed the pressurized dry nitrogen flowing through the porous samples during the air permeability measurement acts as drying the hydrogel triggering shrinking, thus increasing the value of permeability while measuring it.

\subsubsection{Water Permeability Tests}

A second set of experiments consisted of water permeability tests was performed. This method prevents solgel drying and mimics the field conditions in terms of pressure, temperature and saturation 
of the reservoir porosity by equilibrated water. Water permeability measurement gives the true permeability without need for corrections for compressibility and slippage effects.

As described in Section 2.2, the water permeability was measured when the solgel became hydrogel in the pores $\left(k_{g}\right)$ and compared with the initial water permeability of the samples $\left(k_{0}\right)$.

Given the efficiency of the hydrogel sealing, the lowest flow rate value $(Q=0.005 \mathrm{~mL} / \mathrm{min})$ allowed by the experimental system was used. The maximum pressure drop ( $\triangle P=2 \mathrm{MPa}$ ), i.e., about three orders of magnitude higher than that expected in natural conditions, was reached in few tens of minutes for three experiments over four (Figure 8). A key result of these tests is that the hydrogel is not extruded even for these huge values of $\Delta P$ compared to what can be expected in natural environments, even close to the injection location.

The $\Delta P$ increase denotes long-lasting transient processes that unfortunately prevent obtaining a steady state value of the sample permeability, owing to the technical limitation in terms of maximum pressure drop and flow rate mentioned above. These transient processes include the storage effects of both the rock and the hydrogel that probably display an elastoviscoplastic behavior. Nonetheless, the unexpected long duration of the transient effect suggested that pressure increases the sealing capacity of the hydrogel probably by increasing the amount of water trapped in the polymer structure of the hydrogel, thus causing swelling of the hydrogel. For all the experiments performed, the injection was stopped for few minutes (see the steps in the $\Delta P$ curves in Figure 8 ) in order to measure the pressure relaxation trend. At this moment, a slight decrease in $\Delta P$ was observed in all cases indicating that the system has a non-null permeability. One experiment performed with the reefal carbonate (experiment noted M27 in Figure 8) displayed a different behavior in terms of $\Delta P$ variation. The increase in the pressure drop stopped after a few minutes, and then slightly decreased while the water injection was maintained constant. This behavior was not formally explained, but it suggests either some dissolution of the carbonate (slightly undersaturated water composition) or a slow extrusion of the hydrogel due to an incomplete polymerization of the solgel (time to form hydrogel longer than expected). In any case, this apparent failure in the efficiency of the product to decrease the sample permeability indicates that the solgel synthesis and the emplacement procedure must be carefully performed taking into account the chemical properties of the geometrical under consideration.

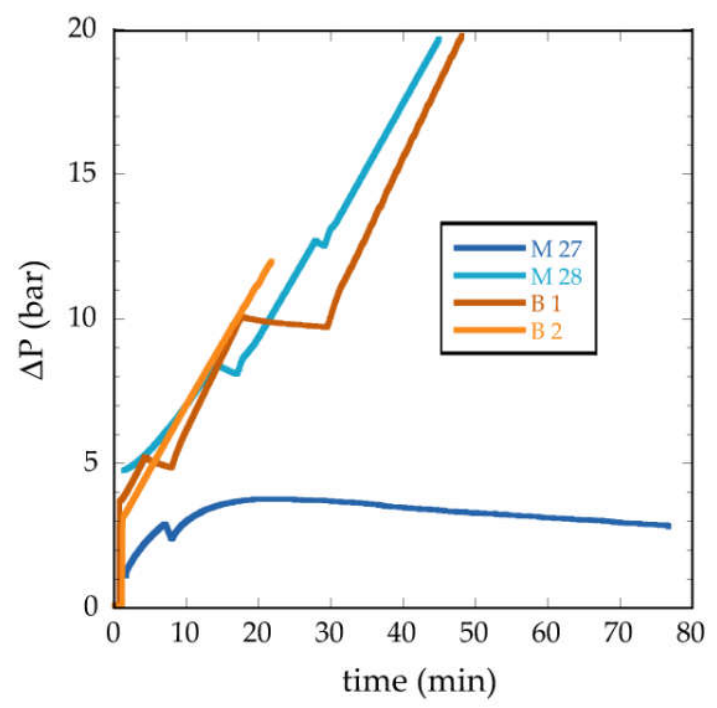

Figure 8. Experimental results for the water permeability tests performed with reefal carbonate (M) and Berea sandstone (B) porous samples. The curves denote the changes in pressure drop $(\Delta P)$ versus time. Experimental data were measured every five seconds. 


\section{Conclusions}

Restoring the sealing capacity of leaky zones (such as fractures) by injecting a self-solidifying fluid is a critical issue as part of the leakage mitigation procedure required for safe $\mathrm{CO}_{2}$ geological storage. Injection of Portland-type cement is the foremost available industrial technique but the limitation of slurry materials to deeply penetrate porous media and thin rough fractures is a well identified issue. The objective of this study was to produce a sealing liquid with better injectivity than Portland cement slurries, while displaying (1) comparable chemical and mechanical stability once emplaced in leaking zones and (2) moderate production cost. The solgel approach was investigated because the final product is an amorphous form of silica which is known to be resistant to acidic fluids. Several steps were needed to meet the specification listed above:

- ETS40-based sol was selected among other silicon alkoxide precursors owing to its affordable price, adequate hydrogel formation time and the ability to produce final materials without fissures.

- The reactant boron oxide was introduced to the synthesis in order to improve the mechanical strength of the resulting material.

- Given that most of the reactions involved in the solgel synthesis using ETS40 were exothermic, no heating of the mixture while preparing or injecting it is required to maintain the product at the right temperature (between 20 and $40^{\circ} \mathrm{C}$ ), thus decreasing the complexity of the surface injection system and the final costs.

- The order of addition of reactants to the bulk solution during the solgel synthesis was found to be a critical parameter to control the temperature of the solgel during its preparation and injection. The different protocols do not affect measurably the final properties of the hydrogel.

- The amount of water and alcohol used in the synthesis was optimized in order to prevent the expulsion of excess liquid in the final product, thus decreasing the amount of reactants needed for the solgel synthesis. Furthermore, this formulation allows the maximum concentration of $\mathrm{Si}$ in the solgel, thus the maximum density of the hydrogel phase.

The aging of the solgel was found to be a crucial process that controls the applicability of this product as a sealant material. The stiff hydrogel material resulting from the aging of the solgel in water-saturated environments (as it is expected at depth) does not display any shrinking. On the contrary, excess pressure seems to decrease the hydrogel density and improve the sealing capacity of the hydrogel. Moreover, the experimental results indicate that the emplacement and capacity of reducing the permeability of the hydrogel formed after aging in water saturated systems does not depend on the degree of water saturation of the reservoir rock before the injection. Apparently, the wettability of the solgel and its low viscosity both act as keeping the amount of trapped residual gas or water very low. As a whole, this study shows that the hydrogel phase, which results from the controlled solgel aging, is a stable product as long as it is maintained hydrated. Importantly its stiffness prevents its extrusion even for very high pressure gradients. This low viscosity, self-solidifying liquid is an attractive alternative to Portland cement slurries, potentially increasing the range of applications for leakage remediation. The next step is to demonstrate its efficiency and long-term chemical stability in monitored operational environments.

Author Contributions: Conceptualization, P.G.; Data curation, M.G.-R.; Formal analysis, M.G.-R.; Methodology, M.G.-R. and P.G.; Writing—original draft, M.G.-R.; Writing—review \& editing, P.G.

Funding: Funding to this work has come from EU FP7 project TRUST, grant agreement number 309067, and EU H2020 FracRisk grant agreement number 636811.

Acknowledgments: Authors acknowledge Marie Guillot and Béatrice Sala for many helpful discussions concerning the fabrication of the solgel mixtures.

Conflicts of Interest: The authors declare no conflict of interest. The funders had no role in the design of the study; in the collection, analyses, or interpretation of data; in the writing of the manuscript, and in the decision to publish the results. 


\section{References}

1. Tsang, C.-F.; Niemi, A. Overview of Processes Occurring during $\mathrm{CO}_{2}$ Geological Storage and Their Relevance to Key Questions of Performance. In Geological Storage of $\mathrm{CO}_{2}$ in Deep Saline Formations. Theory and Applications of Transport in Porous Media, 1st ed.; Niemi, A., Bear, J., Bensabat, J., Eds.; Springer Nature: Dordrecht, The Netherlands, 2017; Volume 29, pp. 15-38, ISBN 978-94-024-0994-9.

2. Manceau, J.-C.; Hatzignatiou, D.G.; de Lary, L.; Jensen, N.B.; Réveillère, A. Mitigation and remediation technologies and practices in case of undesired migration of $\mathrm{CO}_{2}$ from a geological storage unit-Current status. Int. J. Greenh. Gas Control 2014, 22, 272-290. [CrossRef]

3. Shipton, Z.K.; Evans, J.P.; Dockrill, B.; Heath, J.; Williams, A.; Kirchner, D.; Kolesar, P.T. Natural Leaking $\mathrm{CO}_{2}$-Charged Systems as Analogs for Failed Geologic Storage Reservoirs. In Carbon Dioxide Capture for Storage in Deep Geological Formations-Results from $\mathrm{CO}_{2}$ Capture Project, 1st ed.; Benson, S.M., Ed.; Elsevier Ltd.: Oxford, UK, 2005; Volume 2, pp. 699-713, ISBN 0-08-044570-5.

4. Oldenburg, C.M.; Bryant, S.L.; Nicot, J.P. Certification framework based on effective trapping for geologic carbon sequestration. Int. J. Greenh. Gas Control 2009, 3, 444-457. [CrossRef]

5. Watson, T.; Bachu, S. Evaluation of the potential for gas and $\mathrm{CO}_{2}$ leakage along wellbores. SPE Drill. Complet. 2009, 24. [CrossRef]

6. Celia, M.A.; Bachu, S.; Nordbotten, J.M.; Gasda, S.E.; Dahle, H.K. Quantitative Estimation of $\mathrm{CO}_{2}$ Leakage from Geological Storage: Analytical Models, Numerical Models, and Data Needs. In Greenhouse Gas Control Technologies, 1st ed.; Wilson, M., Rubin, E.S., Keith, D.W., Gilboy, C.F., Morris, T., Thambimuthu, K., Gale, J., Eds.; Elsevier Ltd.: Oxford, UK, 2005; Volume 1, pp. 663-671, ISBN 9780080539737.

7. Intergovernmental Panel on Climate Change. Special Report on Carbon Dioxide Capture and Storage, 1st ed.; Cambridge University Press: New York, NY, USA, 2005; ISBN 13978-0-521-86643-9.

8. Kuuskraa, V.A. Overview of Mitigation and remediation Options for Geological Storage of $\mathrm{CO}_{2}$. In Staff Workshop on Technical Papers; AB1925 Report to Legislature; California Institute for Energy and Environment: Berkeley, CA, USA, 28 June 2007.

9. Rodrigues, C.F.A.; Dinis, M.A.P.; Lemos de Sousa, M.J. Review of European energy policies regarding the recent "carbon capture, utilization and storage" technologies scenario and the role of coal seams. Environ. Earth Sci. 2015, 74, 2553-2561. [CrossRef]

10. Bachu, S.; Celia, M. Assessing the Potential for $\mathrm{CO}_{2}$ Leakage, Particularly through Wells, from Geological Storage Sites. In The Science of $\mathrm{CO}_{2}$ Storage; AGU Monograph Series GM148; McPherson, B.J.O.L., Sundquist, E., Eds.; American Geophysical Union: Washington, DC, USA, 2009; pp. 203-216.

11. Benson, S.M.; Hepple, R. Prospects for Early Detection and Options for Remediation of Leakage from $\mathrm{CO}_{2}$ Sequestration Projects. In Carbon Dioxide Capture for Storage in Deep Geologic Formations; Thomas, D.C., Benson, S.M., Eds.; Elsevier Ltd.: Oxford, UK, 2005; Volume 2, ISBN 9780080445700.

12. Esposito, A.; Benson, S.M. Remediation of possible leakage from geologic $\mathrm{CO}_{2}$ storage reservoirs into groundwater aquifers. Energy Procedia 2011, 4, 3216-3223. [CrossRef]

13. Loizzo, M.; Akemu, O.A.P.; Jammes, L.; Desroches, J.; Lombardi, S.; Annunziatellis, A. Quantifying the risk of $\mathrm{CO}_{2}$ leakage through wellbores. SPE Drill. Complet. 2011, 26. [CrossRef]

14. Deremble, L.; Loizzo, M.; Huet, B.; Lecampion, B.; Quesada, D. Stability of a leakage pathway in a cemented annulus. Energy Procedia 2011, 4, 5283-5290. [CrossRef]

15. Kutchko, B.G.; Strazisar, B.R.; Dzombak, D.A.; Lowry, G.V.; Thaulow, N. Degradation of well cement by $\mathrm{CO}_{2}$ under geologic sequestration conditions. Environ. Sci. Technol. 2007, 41, 4787-4792. [CrossRef] [PubMed]

16. Abdoulghafour, H.; Luquot, L.; Gouze, P. Characterization of the mechanisms controlling the permeability changes of fractured cements flowed through by $\mathrm{CO}_{2}$-rich brine. Environ. Sci. Technol. 2013, 47, 10332-10338. [CrossRef] [PubMed]

17. Davidovitch, J. Geopolymer Chemistry and Applications, 4th ed.; Institut Géopolymère: Saint-Quentin, France, 2015; ISBN 9782951482098.

18. Nasvi, M.M.C.; Gamage, R.P.; Jay, S. Geopolymer as well cement and the variation of its mechanical behavior with curing temperature. Greenh. Gases Sci. Technol. 2012, 2, 46-58. [CrossRef]

19. Shaw, J.C.; Bramhill, B.; Wardlaw, N.C.; Costerton, J.W. Bacteria fouling in a model core system. Appl. Environ. Microbiol. 1985, 49, 693-701. [PubMed] 
20. Cunningham, A.B.; Gerlach, R.; Spangler, L.; Mitchell, A.C.; Parks, S.; Phillips, A. Reducing the risk of well bore leakage of $\mathrm{CO}_{2}$ using engineered biomineralization barriers. Energy Procedia 2011, 4, 5178-5185. [CrossRef]

21. Phillips, A.J.; Lauchnor, E.; Eldring, J.; Esposito, R.; Mitchell, A.C.; Gerlach, R.; Cunningham, A.B.; Spangler, L.H. Potential $\mathrm{CO}_{2}$ leakage reduction through biofilm-induced calcium carbonate precipitation. Environ. Sci. Technol. 2013, 47, 142-149. [CrossRef] [PubMed]

22. DiCarlo, D.A.; Aminzadeh, B.; Roberts, M.; Chung, D.H.; Bryant, S.L.; Huh, C. Mobility control through spontaneous formation of nanoparticle stabilized emulsions. Geophys. Res. Lett. 2011, 38. [CrossRef]

23. Yu, J.; An, C.; Mo, D.; Liu, N.; Lee, R. Foam mobility control for nanoparticle-stabilized supercritical $\mathrm{CO}_{2}$ foam. In Proceedings of the Improved Oil Recovery Symposium, Tulsa, OK, USA, 14-18 April 2012; Society of Petroleum Engineers: Richardson, TX, USA, 2012.

24. Aminzadeh, B.; Chung, D.H.; Bryant, S.L.; Huh, C.; Dicarlo, D.A. $\mathrm{CO}_{2}$ leakage prevention by introducing engineered nanoparticles to the in-situ brine. Energy Procedia 2013, 37, 5290-5297. [CrossRef]

25. Farhadi, H.; Riahi, S.; Ayatollahi, S.; Ahmadi, H. Experimental study of nanoparticle-surfactant-stabilized $\mathrm{CO}_{2}$ foam: Stability and mobility control. Chem. Eng. Res. Des. 2016, 111, 449-460. [CrossRef]

26. Sheng, J.J. Modern Chemical Enhanced Oil Recovery-Theory and Practice, 1st ed.; Gulf Professional Publishing: Burlington, MA, USA, 2010; ISBN 978-1-85617-745-0.

27. Syed, A.; Pantin, B.; Durucan, S.; Korre, A.; Shi, J.-Q. The use of polymer-gel solutions for remediation of potential $\mathrm{CO}_{2}$ leakage from storage reservoirs. Energy Procedia 2014, 63, 4638-4645. [CrossRef]

28. Lakatos, I.; Lakatos-Szabó, J.; Tiszai, G.; Palaásthy, G.; Kosztin, B.; Trömböczky, S.; Bodola, M.; Patterman-Farkas, G. Application of silicate-based well treatment techniques at the Hungarian oil fields. In Proceedings of the SPE Annual Technical Conference and Exhibition, Houston, TX, USA, 3-6 October 1999; Society of Petroleum Engineers: Houston, TX, USA.

29. Tittelboom, K.V.; De Belie, N.; De Muynck, W.; Verstraete, W. Use of bacteria to repair cracks in concrete. Cement Concr. Res. 2010, 40, 157-166. [CrossRef]

30. Blue, A.J. Experimental Evaluations of Selected Sealants to Remediate $\mathrm{CO}_{2}$ Leakage. Master's Thesis, Missouri University of Science and Technology, Rolla, MO, USA, 2016.

31. Castañeda-Herrera, C.A.; Black, J.R.; Stevens, G.W.; Haese, R.R. Preliminary experiments for a chemical reactive barrier as a leakage mitigation technology. Energy Procedia 2017, 114, 4140-4146. [CrossRef]

32. Ito, T.; $\mathrm{Xu}, \mathrm{T}$.; Tanaka, H.; Taniuchi, Y.; Okamoto, A. Possibility to remedy $\mathrm{CO}_{2}$ leakage from geological reservoir using $\mathrm{CO}_{2}$ reactive grout. Int. J. Greenh. Gas. Control. 2014, 20, 310-323. [CrossRef]

33. Brinker, C.J.; Scherer, G.W. Sol-Gel Science. The Physics and Chemistry of Sol-Gel Processing, 1st ed.; Academic Press, Inc.: San Diego, CA, USA, 1990; ISBN 0-12-134970-5.

34. Dimitriev, Y.; Ivanova, Y.; Iordanova, R. History of sol-gel science and technology (Review). J. Univ. Chem. Technol. Metall. 2008, 43, 181-192.

35. Milea, C.A.; Bogatu, C.; Duta, A. The influence of parameters in silica sol-gel process. Bull. Transilv. Univ. Brasov 2011, 4, 59-66.

36. Zarzycki, J. Past and present of sol-gel science and technology. J. Sol.-Gel. Sci. Technol. 1997, 8, 17-22. [CrossRef]

37. Hamd, W. Elaboration Par Voie Sol-Gel et Etude Microstructurale de Gels et de Couches Minces de $\mathrm{SnO}_{2}$. Master's Thesis, Limoges University, Limoges, France, 14 December 2009.

38. Barboiu, C.; Sala, B.; Bec, S.; Pavan, S.; Petit, E.; Colomban, P.; Sanchez, J.; de Perthuis, S.; Hittner, D. Structural and mechanical characterizations of microporous silica-boron membranes for gas separation. J. Membr. Sci. 2009, 326, 514-525. [CrossRef]

39. Gouze, P.; Le Borgne, T.; Leprovost, R.; Lods, G.; Poidras, T.; Pezard, P. Non-Fickian dispersion in porous media: 1. Multiscale measurements using single-well injection withdrawal tracer tests. Water Resour. Res. 2008, 44. [CrossRef]

40. Siena, M.; Riva, M.; Giamberini, M.; Gouze, P.; Guadagnini, A. Statistical modeling of gas-permeability spatial variability along a limestone core. Spat. Stat. 2017. [CrossRef]

41. Scheidegger, A.E. The Physics of Flow through Porous Media, 3rd ed.; University of Toronto Press: Toronto, ON, Canada, 1974; ISBN 0802018491. 
42. Klinkenberg, L.J. The permeability of porous media to liquids and gases. In Proceedings of the Drilling and Production Practices, New York, NY, USA, 1 January 1941; American Petroleum Institute: Washington, DC, USA.

43. Luquot, L.; Gouze, P. Experimental determination of porosity and permeability changes induced by injection of $\mathrm{CO}_{2}$ into carbonate rocks. Chem. Geol. 2009, 265, 148-159. [CrossRef]

44. Klein, L.C. Sol-Gel processing of silicates. Ann. Rev. Mater. Sci. 1985, 15, 227-248. [CrossRef] 